\title{
Antiviral and virucidal effects of plant aqueous extracts against Herpes simplex and Encephalomyocarditis murine viruses
}

\author{
Barra, M. , Barbosa, N*, Resende, F. , Alves de Matos, A.P. ${ }^{* *}$, Falé, P.L. ${ }^{* * *}$, Ascensão, L. ${ }^{* * * *}$, \\ Serralheiro, M.L.M. ${ }^{* * *}$, Caeiro, M.F.
}

*CESAM, Centro de Estudos do Ambiente e do Mar, Faculdade de Ciências da Universidade de Lisboa, Departamento de Biologia Vegetal, Campo Grande, 1749-016, Lisboa, PORTUGAL

***ESAM, Centro de Estudos do Ambiente e do Mar, Centro Hospitalar de Lisboa Central - HCC, Anatomia Patológica, R. Da Beneficência 8, 1069-166, Lisboa, PORTUGAL

**** Centro Química e Bioquímica, Faculdade de Ciências da Universidade de Lisboa, Departamento de Química e Bioquímica, Campo Grande, 1749-01 6, Lisboa, PORTUGAL

***** Universidade de Lisboa, Faculdade de Ciências de Lisboa, DBV, IBB, Centro de Biotecnologia Vegetal, C2, Campo Grande, 1749-016 Lisboa, PORTUGAL

email: mfcaeiro@fc.ul.pt

The significant increase of Herpes simplex virus (HSV) strains resistant to commonly used clinical medicines and the lack of antiviral drugs for most viruses, such as the Picornaviridae, led to an intense search for new bioactive compounds [1,2]. Higher plants are still an important source of widely used pharmaceutics. Many of these pharmacologically active compounds are present in plant aqueous extracts, the common teas of medicinal herbs. The present study aimed to evaluate the anti-herpetic and anti-picornavirus activities of extracts obtained by decoction of leaves/stems and flowers of three Asteraceae species of the Portuguese aromatic flora (Helichrysum italicum, Solidago virgaurea and Santolina impressa) and a Lamiaceae species (Plectranthus barbatus), cultivated in Portugal and commonly used in Brazil for the treatment of several ailments. The extracts of the referred species are designed by numbers $3,4,6$, and 8 .

The human Herpes simplex virus types I and II (HSV-I and HSV-II) and the Encephalomiocarditis murine virus (EMCV), a non-human virus representative of the Picornaviridae, were selected for this study. The activities of the extracts were tested in non-cytotoxic concentrations for VERO cells, parameter previously determined by the MTT test [3]. Results (inhibitions in the production of infectious virus) are expressed in percentages, relative to the titers obtained in control conditions (non-treated infected cells). Extracts (and no extract in control conditions) were added to VERO cells after infection with EMCV, HSV-I or HSV-II. Eight or twenty four hours post infection, respectively for EMCV or for the herpes viruses, the intracellular virus associated to cells and cell debris was collected and subjected to titration by plaque reduction assays [1]. In parallel, treated and non-treated control and infected cells were also collected $18 \mathrm{~h}$ post infection to perform transmission electron microscopy (TEM) studies, using conventional fixation and embedding methods previously described [4].

Extracts exhibited diverse inhibitory effects in the production of infectious virus particles in VERO cells, during the replication cycle of these viruses. EMCV production was mainly inhibited by extract $6(99.3 \%)$ and in a lesser extent (less than $90 \%$ but over $50 \%$ ) by extracts 4,3 and 8 . HSV-1 production was mainly inhibited by extracts 8 and 3 (99.7\% and 95.7\%, respectively) and less than $90 \%$ but over $50 \%$ by extracts 9 , 4 and $6 . \mathrm{HSV}-2$ production was inhibited more than $90 \%$ by all the extracts, with the exception of extract 9 (20\% inhibition). TEM observations of HSV-1 and HSV-2 morphogenesis in the cells treated with the strongest inhibitory extracts showed in all cases residual production of nucleocapsids in the nucleus (Fig. 1A), and occasional particles in the cytoplasm budding into Golgi apparatus vesicles (Fig.1B). Extracellular particles were also observed (Fig. 1C). These ultrastructural features suggest that the viruses are still able to 
go through the complete morphogenetic cycle in the treated cells in spite of strong quantitative decrease in infectivity. Extracellular particles often showed an abnormal morphology, suggesting that they may not represent active virions.

The inhibitory effect on virus yields, when infected cells are treated with some of these extracts, is a relevant result, principally for EMCV and HSV-1, whose virus particles showed little or even no susceptibility to the extracts, in experiments of virucidal activity (data not shown). According to this criterion, extracts 6 and 9 may be particularly promising, respectively for EMCV and HSV-1. HSV-2 production in infected cells was highly affected by the extracts (exception for extract 9), in a higher level than the corresponding virucidal effects (data not shown). Present results concerning the effect of these plant aqueous extracts against HSV- I, HSV-II and EMCV justify the ongoing additional work, in an attempt to understand the mechanism/s of action involved in these antiviral responses.

Study partially funded by Fundação para a Ciência e a Tecnologia under PEst-C/MAR/LA0017/2013, PEstE/EQB/LA0023/2011, PEst-OE/QUI/UI0612/2013.

\section{References}

[1] Resende F., Master Thesis, Faculty of Sciences, Lisbon University, 50 pp, 2012.

[2] Norder H. et al., Antiviral Res., 89, 204-218, 2011.

[3] Mossman T.J, Immunol. Methods, 65, 55-63, 1983.

[4] Alves de Matos A.P. et al., Microsc. Microanal., 17, 101-108, 2011.

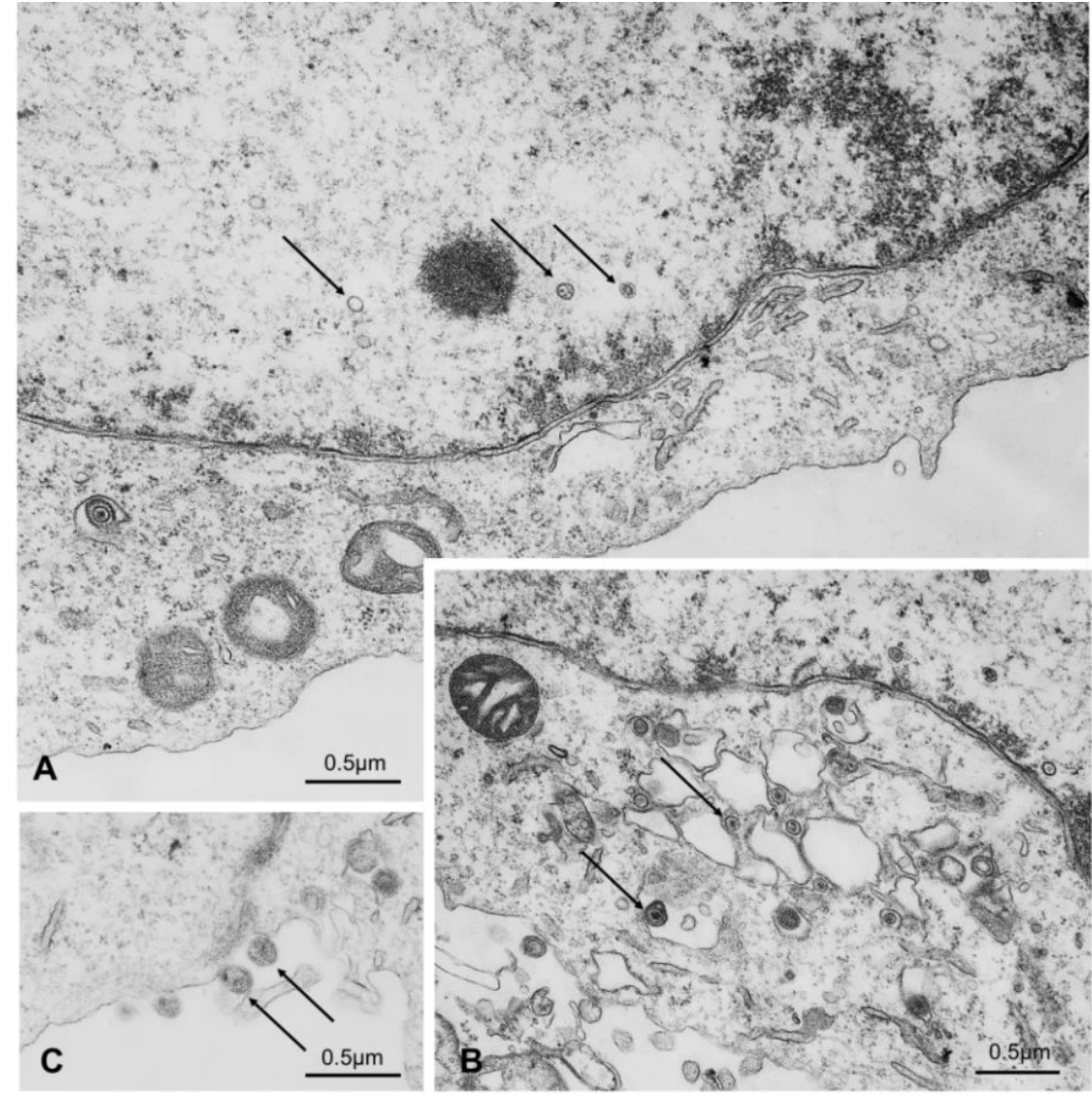

Fig. 1 - Transmission electron micrographs of HSV-1 infected cells treated with extract 3 .

A, Inside the infected nucleus only a few nucleocapsids (arrows) are found. B, Virus particles are clearly seen associated with the Golgi (arrows). C, Extracellular particles with indistinct internal morphology (arrows) are observed. 